\title{
Resilience and Suicide Risk of Overseas Filipino Domestic Helpers
}

\author{
Arabella Kay M. Nerosa \\ Healthlink, Inc., Iloilo City, Philippines \\ arabellenerosa@gmail.com \\ https://orcid.org/0000-0002-8940-679X
}

\begin{abstract}
Filipinos are naturally resilient. However, there are increasing cases of suicide among overseas workers. This study determined the level of resilience and suicide risk of overseas Filipino domestic helpers, with consideration to their demographic variables like age, civil status, educational attainment, religion, and work experience abroad. Using a descriptive-correlational design, it also assessed the relationship between resilience and suicide risk. Fifty-one overseas Filipino domestic helpers were obtained through snowball sampling. Data were gathered through Resilience Research CenterAdult Resilience Measure and Revised Suicide Behavior Questionnaire and were analyzed through mean, Fisher Exact, and Pearson r. Results revealed a high resilience level and low suicide risk. There were also no significant relationships between resilience, suicide risk, and demographic variables. Likewise, there is no significant relationship between resilience and suicide risk. Filipino domestic helpers demonstrated the capacity to overcome adversities. Findings may serve as a basis for a proposed pre-deployment enhancement training program for overseas Filipino domestic helpers.
\end{abstract}

Keywords: Psychology, Resilience, Suicide Risk, Overseas Filipino Domestic Helpers, Descriptive-Correlational, Iloilo, Philippines 